Arteterapia. Papeles de arteterapia y educación para inclusión social ISSN: $1886-6190$

\title{
Espacios de encuentro y co-responsabilidad. El niño como referencia para el crecimiento personal del adulto.
}

\author{
Marina Ojeda López ${ }^{1}$
}

Recibido: 30 de junio de 2016 / Aceptado: 26 de agosto de 2016

Resumen. En el trabajo terapéutico y creativo con niños, se hace necesario involucrar a los padres, dándoles la responsabilidad de trabajar en sus propios procesos personales. El niño hace visible dinámicas familiares que debemos revisar y también invita al adulto a encontrarse consigo mismo, con una parte de él instintiva y libre, que necesita ser rescatada. El espacio creador invita a cada miembro de la familia a reencontrase, a cuestionarse y a descubrirse en uno mismo, en la relación de pareja y en la relación con la familia de origen. Éste es un proceso creativo que se convierte en una maravillosa herencia para los más pequeños.

Palabras clave: Procesos personales; niños; familia; creativo.

\section{[en] Grounds for discovery and shared responsibility. The child as the basis for adult self-development}

\begin{abstract}
In therapeutic and creative work with children, involving parents is key. Parents can use it as an opportunity to work at their own personal development. Through the child, significant family dynamics that need attention may be uncovered and thus parents are encouraged to look inside themselves and rediscover their true, authentic selves. In this creative ground members of the family are invited to find themselves anew, to question and rediscover themselves and the true nature of their relationship with partner.
\end{abstract}

Keywords: Personal processes; children; family; creative.

Sumario. 1. Introducción; 2. La familia en la intervención con niños. Co-responsabilidad; 3. Revisión de roles; 4. Caracteres y alianzas; 5 . Límites con amor; 6 . Construyendo el ser padres y madres. Una mirada a la relación de pareja; 7. El desarrollo personal de los padres; 8 . El niño interior. Un acercamiento a los niños desde la propia vivencia. La sabiduría del niño; 9. Explorando emociones. Mapa emocional en la familia; 10. Recuperar espacios de exploración y disfrute; 11. Reflexiones finales; 12. Referencias bibliográficas.

Cómo citar: Ojeda López, M. (2016) Espacios de encuentro y co-responsabilidad. El niño como referencia para el crecimiento personal del adulto, en Arteterapia. Papeles de arteterapia y educación para inclusión social 11, 193-208.

1 Arteterapeuta. Terapeuta Gestalt. Experta en Intervención Psicosocial. Docente y supervisora en el Máster de Arteterapia de la UPO, Sevilla. Artista plastic.

E-mail: marinaojeda_arteterapia@hotmail.com 


\section{Introducción}

Mi intención en este artículo es hacer una reflexión a cerca del trabajo que vengo desarrollando desde hace años en contacto directo con niños y familias, haya sido en contextos de creación libre o bien en contextos terapéuticos o grupos de habilidades parentales. En este recorrido que he ido construyendo como profesional, también he ido viviendo y creciendo como persona, sumando experiencias, revisando planteamientos y dando forma a una manera propia de trabajar y de entender a los niños y niñas, siempre en relación directa con su familia y contextos más cercanos.

Ha sido especialmente relevante para mí el darme cuenta de que como adultos tenemos una clara responsabilidad con nosotros mismos, responsabilidad que repercute directa y claramente en la educación y crianza de los más pequeños. Nuestros introyectos, expectativas, frustraciones y dificultades se actualizan una y otra vez en relación con el otro y son los niños claros espejos en los que podemos revisar nuestro niño interior que, muchas veces no ha sido lo suficientemente atendido, escuchado y valorado. Desde mi formación como arteterapeuta y como terapeuta gestalt, e incluyendo otros planteamientos de intervención como las constelaciones familiares, me planteo todas éstas cuestiones que aquí comparto con vosotros, exponiendo mis ideas, reflexiones e inquietudes en torno a la construcción y crecimiento de la familia y de cada uno de sus miembros.

\section{La familia en la intervención con menores. Co-responsabilidad}

En el trabajo en consulta de Arteterapia individual o grupal con niños y adolescentes, resulta ser muy relevante el grado de motivación e implicación de los padres en el proceso de sus hijos, en tanto en cuanto sean capaces de asumir su responsabilidad con respecto a la dificultad por la que su hijos atraviesan. Son muchos casos en los que los padres no toman parte en el proceso y se sienten fuera del campo que los compromete como partes directamente vinculadas con la experiencia de los pequeños. Es entonces cuando es necesario plantear una nueva mirada hacia esa estructura familiar e integrar este trabajo con la familia dentro del proceso terapéutico y/o creativo con el menor. Para ello son necesarias las entrevistas con los padres, las tareas enfocadas a entender el concepto de coresponsabilidad con el que trabajamos, comprendiendo la terapia como un proyecto común y compartido. Eso nos invita a valorar un nuevo reajuste de la familia, entendida ésta como un encuentro dinámico y creativo entre cada uno de los miembros que la componen. Y esta concepción de la intervención terapéutica requiere un aprendizaje por parte de los padres, una salida de la zona de confort y una exploración en otros espacios donde normalmente no solemos movemos. Simplemente el cuestionar nuestras verdades y nuestras maneras, nos permite adoptar una nueva perspectiva, permitiendo que surjan otras posibilidades y con ello, nuevas dinámicas y movimientos.

En este proceso en búsqueda de la co-responsabilidad, las expectativas puestas en el terapeuta como salvador, como persona que sabe, como poseedor de la verdad, van difuminándose y dando lugar a una figura distinta, mucho menos idealizada y entendida como un eje vertebrador que acompaña y sostiene, que 
denuncia y confronta, que sirve de apoyo y de referencia en este descubrir continuo. El terapeuta a su vez debe hacerse cargo del lugar que ocupa y desmitificarlo, acercándose a los padres con respeto y una actitud abierta, entendiendo que los padres hacen lo que pueden con los recursos que tienen. Y entonces, desde ese respeto, es posible que el foco del trabajo se re-ubique de nuevo en su lugar, en la familia y en la confianza, en su capacidad de autoregularse, de movilizarse para alcanzar el equilibrio que buscan y necesitan. (Ver fig 1 . Imagen de una sesión de Arteterapia grupal con hijos de mujeres víctimas de violencia. "Mi familia completa").
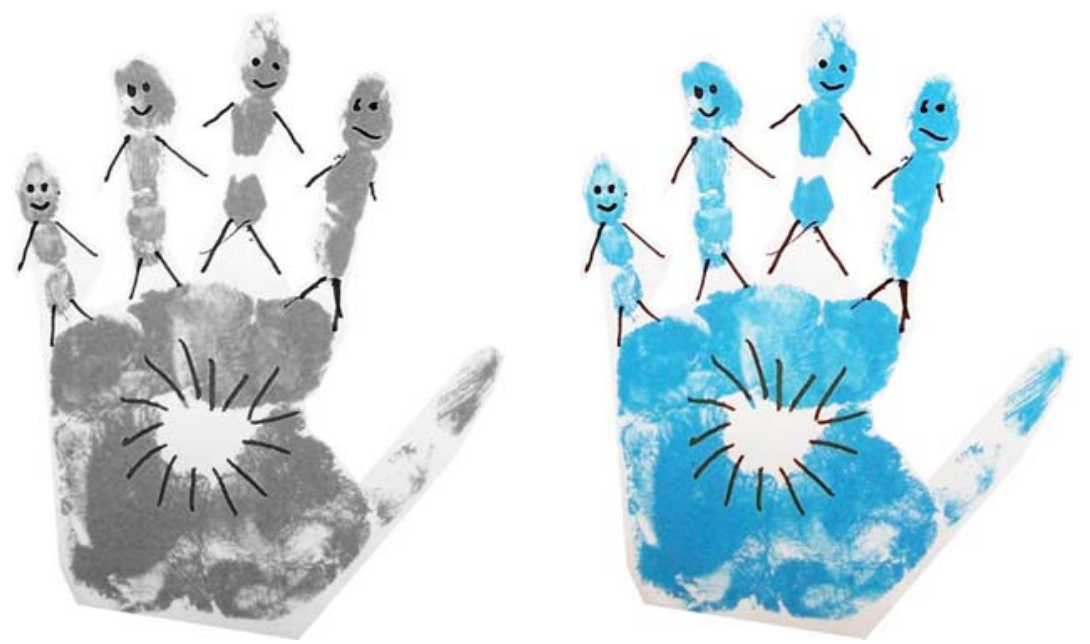

Figura 1. Mi familia completa

El mensaje sería:"Yo como terapeuta hago mi parte y vosotros como madre y padre haces también vuestra parte para que este niño o niña encuentre su sitio, el sitio que le corresponde".

La complicidad entre padres y terapeuta es piedra angular del trabajo en arteterapia, entendiendo que el pequeño es la parte más vulnerable de la familia y que depende de este entendimiento y confianza mutua, que el trabajo sea provechoso.

En este trabajo de co-responsabilidad cada una de las partes tienen su tarea y también el niño puede dedicarse a lo que le ocupa: a ser niño, entendiendo que sus padres se encargan de "cosas de mayores" donde él no puede ni debe interferir.

\section{Revisión de roles}

Desde un primer momento, al recibir a una familia, me planteo cómo está siendo para ellos el reparto de roles y de qué manera están funcionando, la mayoría de las veces sin darse cuenta. Aquí entran en juego aspectos sociales y culturales, patrones familiares heredados y a su vez, independientemente del modelo familiar 
más o menos tradicional, es interesante observar si cada uno de los miembros de la familia está en el lugar que le corresponde, como madre, padre e hijo.

Las mujeres que se adjudican el rol de "madres de sus parejas", asumen la responsabilidad de educar, sostener emocionalmente e incluso decidir por la pareja la dirección a seguir. Por otro lado, las mujeres que se comportan como "hijas de sus parejas", buscan que haya un otro que la proteja, la cuide y la acoja de manera paternal e incondicional. Y lo mismo ocurre por parte de los hombres que actúan como "hijos de sus mujeres o padres de las mismas".

Por su parte los hijos, en muchas ocasiones creen coger fuerza aliándose con su madre y colocándose por encima del padre, ocupando un lugar demasiado pesado para ellos y haciéndose cargo de situaciones que no les corresponden. $\mathrm{O}$ al revés, se alían con el padre, desplazando a la madre a un segundo lugar. A veces son los propios progenitores los que, en su propio beneficio se alían con los hijos en contra de la pareja, poniendo a los hijos en situaciones de mucha tensión. Y entonces desde nuestra perspectiva como Arteterapeutas, nos toca reclamar que todo ésto es responsabilidad de los adultos, que nosotros somos los que tenemos recursos y la posibilidad de mirar más ampliamente, por encima de lo conocido, más allá de lo aparente, desde la madurez que la edad nos otorga o buscando la manera de trascender las limitaciones que por cultura, falta de recursos o carácter, nos entorpecen para construir familias sanas.

Es de una manera inconsciente que vamos desencajándonos del lugar que nos corresponde, como si de un puzzle se tratara, dejándonos mover por esos hilos invisibles que nos tiran hacia un lado o hacia otro, dependiendo de las dinámicas intrafamiliares y del carácter que desarrollamos desde la infancia.

En la consulta de Arteterapia Gestalt, al comienzo del proceso, busco la manera de visualizar estas ambivalencias gracias al uso de muñecos y objetos, dejando que en estas "escenas de familia" aparezcan los elementos emergentes con los que trabajaremos a lo largo del proceso de la terapia. Re-crear escenas es una manera lúdica y creativa de poner las cartas sobre la mesa, de visibilizar las alianzas, los espacios de encuentro y desencuentro, la proximidad o las distancias, etc.

La simple posibilidad de movilizar los muñecos y probar otras opciones, nos coloca en una perspectiva distinta, en un lugar creador donde la persona toma conciencia de su posibilidad de cambio, de modificar la perspectiva desde donde ve y entiende la relación de familia y de comprender que es su elección permanecer en el mismo lugar o buscar alternativas.

Esta revisión de roles implica, por un lado, explorar alternativas de manera simbólica, utilizando el potencial de la imagen para generar un nuevo mapa con nuevos espacios, recorridos, posibilidades. Por otro, entrar en contacto con necesidades propias, emociones no expresadas, sensaciones a nivel corporal que se actualizan en la escena y nos permiten indagar en patrones de comportamiento recurrentes y que, de alguna manera han dejado de ser satisfactorios. Esta experiencia puede repetirse a lo largo del proceso todas las veces que sea necesario, ya sea con objetos y muñecos o bien con anclajes de tela que representen a los diferentes componentes de la la familia, pudiendo ubicarlos en el espacio y movernos de uno a otro, dejándonos estar y sentir en cada uno de ellos. 


\section{Caracteres y alianzas}

Es obvio que el carácter nos marca y nos condiciona a la hora de relacionarnos con los demás y más aún dentro de la familia, en esos espacios estrechos y concurridos, en los que se visibiliza con mayor claridad nuestras maneras, tendencias, carencias y movimientos inconscientes.

La patología principal cuando trabajamos con parejas y con familias es el empeño que ponen las personas en dividir el mundo y a los miembros familiares en buenos y malos. De hecho es la semilla de todas las guerras. Algo se arregla y se reconcilia o se construye cuando todos pueden ser respetados y preservar su dignidad. Demasiadas personas sufren en su corazón por sentir que a un padre le dan el lugar del bueno y a otro el lugar del malo y así perpetúan la guerra interior.

(Garriga, 2005).

Dentro de la pareja, el otro actúa como un espejo en el que puedo reconocer con mayor facilidad que en cualquier otro lado mis sombras, mis heridas infantiles que se reactivan en contacto con esa persona, mis carencias y expectativas puestas de manera incisiva en otro que está enfrente, muy cerca, pero que no soy yo. Es por eso que, cuando las relaciones de los adultos fallan o no están funcionando de una manera clara, los hijos sirven muchas veces para movilizar alianzas, para crear frentes comunes, maneras de sostenernos en la diferencia y de alimentar nuestras dificultades para explorarnos a través del otro, esa parte de nosotros que tanto nos cuesta reconocer. Los hijos, por amor y lealtad, entran a formar pactos inconscientes con alguno de sus progenitores, ocupando huecos que ellos dejan, sintiéndose así importantes y necesarios, alimentando así también la estructura de su carácter, un carácter que empieza a formarse temprano y que a medida que pasa el tiempo se va afianzando y consolidando como una armadura que nos ayuda a enfrentar el mundo y la vida que nos toca vivir.

Es por eso que en el proceso de la terapia, se visibilizan estos pactos y entonces podemos empezar a darnos cuenta de cómo por miedo, inseguridad y falta de autoestima, vamos pidiendo a los hijos, sin pedirlo, que se hagan cargo de los mayores, que hagan lo que ellos no pudieron hacer por sí mismos, que respondan como deberían responder, según nuestros esquemas e introyectos, que ocupen esos espacios para que nosotros no sintamos el hueco, el vacío, la carencia.

Desde el lugar de adultos dentro de una familia, la mayor alianza que podemos trabajar es la de ponernos en sintonía con la pareja, para crecer en ella y dar a los hijos una imagen clara de encuentro y equilibrio entre esas dos partes que configuran al niño en la misma proporción: su padre y su madre.

\section{Límites con amor}

Observo muy de cerca cuánto miedo hay en las familias actuales de decir No a los hijos, de no darles todo, de permitir que se sientan frustrados, de soportar que sientan la dificultad que entraña el crecer y el vivir como niños. También surge el miedo en muchos adultos a no ser lo suficientemente buenos como padres y 
madres, a no dar la talla, a que sus hijos vean y conozcan la realidad de la vida con su abundancia y también con sus carencias, con sus logros y sus fracasos, con sus aciertos y sus errores. Así, deberíamos plantearnos cuánta dificultad tenemos para sostener el dolor y el malestar, lo incómodo, lo difícil.

$\mathrm{Y}$ ante esta dificultad, los límites necesarios para su crecimiento se difuminan, se desvanecen, se pierden. Mucho del trabajo en la consulta de Arteterapia Gestalt es reencauzar y recolocar las piezas del puzzle para que cada uno vuelva a su lugar, para que cada cual tome su sitio y desde ahí pueda continuar. Éste movimiento de reajuste pasa por marcar de una manera clara los límites necesarios para que los niños y niñas crezcan seguros y protegidos. Esa es la principal función de los límites. Al igual que en el trabajo en la consulta marcamos un encuadre seguro que nos permita movernos a lo largo del proceso con seguridad y claridad, en las familias ocurre lo mismo. Este encuadre es necesario para no criar a niños déspotas, abusivos, intolerantes y manipuladores.

También es cierto que los límites antiguamente estaban asociados con la imposición y el castigo, con el abuso de poder y de autoridad. Pero es posible marcar estos límites también desde el amor, desde la calma, el respeto y el entendimiento. Un No rotundo y claro también es amoroso y así un niño aprende a moverse en un espacio donde sabe que hay cuidado, que hay margen, pero protegido. Estos límites serán renegociados y ampliados en la medida en que el niño vaya creciendo y vaya integrando dentro de sí mismo ese sentido de la responsabilidad y de la autogestión.

La gran dificultad aparece cuando son los mayores quieres no son capaces de reconocer sus propios límites, quienes no han incorporado esta estructura dentro de sí mismos. Por eso de nuevo, nos manejamos en un contexto de co-responsabilidad en el que los padres deben reconocer su dificultad y trabajar en ella, cuestionarse lo aprendido y considerado "normal" para poder expandir su experiencia en el contexto de la familia.

Si estos límites con amor se construyen desde lo positivo, desde una actitud que abre en lugar de cerrar, que ofrece posibilidades en lugar de imponer respuestas, que ayuda al niño a crecer de manera consecuente y en armonía, entonces, podremos ver cómo los límites, lejos de ser considerados como restricciones, conforman maravillosos espacios de acogida y sostén, de exploración y crecimiento fértil. Y ésto, como todo, es una tarea compartida entre padres e hijos.

\section{Construyendo el ser padres y madres. Una mirada a la relación de pareja}

Cada vez con mayor claridad observo en las sesiones de Arteterapia Gestalt cómo la dificultad de los niños proviene en muchos casos de la difícil relación entre sus padres, de la incapacidad de uno de ellos para reconocer al otro, darle su lugar, respetarlo en sus maneras, darle al hijo la certeza de que esa persona es el mejor madre o padre que pueda tener o, al menos, el que la vida le da para que con ello, crezca y saque lo mejor de sí mismo. El reconocimiento y la aceptación de la pareja es un trabajo que tenemos por delante no sólo para crecer en relaciones sanas y amorosas sino que, para aquellos que decidan tener hijos, se convierte en un requisito ineludible al que hacer frente por el bien de la familia y del pequeño.

La dificultad de mirarnos a nosotros mismos y esa tendencia a proyectar fuera 
nuestra necesidad para no escucharnos, para no atendernos, puede acrecentarse en la relación de pareja y con la llegada de los niños aún más. Tanta expectación, atención, tanto amor y por supuesto tanta demanda unida a la lógica dependencia y necesidad del niño con respecto a los padres, generan un movimiento de desenfoque temporal en el que la pareja deja de mirarse, de atenderse mutuamente, de acordarse de que lo que ha generado una nueva vida ha sido el amor mutuo y que éste debe ser tenido en cuenta con cariño y cuidado.

Incluso cuando la pareja no continúa unida, si somos capaces de hacer un duelo amoroso, podemos regalar a los hijos esa imagen de amor por lo que hubo, por lo que fue y por lo que en él encarnado sigue habiendo.

Los niños necesitan ser respetados en esa unidad que son, mezcla perfecta de dos partes que aportan cada una su $50 \%$. Es en ese respeto donde un niño crece y confía, sabiendo que él es querido y aceptado en sí mismo, sin verse en la necesidad de alienar partes de él o rechazar a uno de sus padres en él. Las consecuencias que tiene esa dificultad de los adultos en la vida de los pequeños son muy importantes. Y el trabajo podría comenzar por atender mi dificultad con el otro, expresar lo no dicho, compartir mis deseos, mis carencias, aceptar que el otro no está aquí para salvarme, que soy yo quién no se cuida, quién no se atiende, quién no se permite, que el otro hace lo que puede con su dificultad y que en esta coyuntura nos encontramos, quizás remediablemente, quizás sin una solución que no sea un "gracias" y "hasta luego".

Sea como sea, en la medida que tomamos consciencia de nuestra responsabilidad, vamos liberando a los hijos de la dura tarea de tener que tomar parte, de tener que posicionarse a favor de uno y en contra del otro, de soltar lo que no le corresponde como niño y aprender a vivir integrando todas las partes de su ser.

La pareja es una relación entre adultos y no materno o paterno filial. Cuando las demandas y expectativas hacia la pareja son enormes se hace necesario girar la mirada hacia los padres y revisar los asuntos pendientes y tomar de ellos lo que no pudo ser tomado. Las personas que consiguen restaurar el vínculo amoroso con sus orígenes y tomar lo que vivieron tal como fue se dirigen a la pareja con expectativas más razonables y adultas. Para decirlo simplemente, ya no actúan como huérfanos. La relación materna filial se funda en la desigualdad y en el control de los impulsos sexuales; en cambio la relación de pareja se funda en la igualdad de rango y en la entrega sexual.

(Garriga, 2005).

\section{El desarrollo personal de los padres}

Cada vez existen más contextos en los que se trabajan las llamadas habilidades parentales, recursos que se ofrecen para gestionar las dificultades que implican la crianza y el crecer en familia.

He tenido la oportunidad de trabajar con grupos de padres y madres en diferentes contextos: grupos de habilidades parentales, talleres de Creatividad, Arteterapia en familia, Arteterapia para niñas y niños, consulta individual de 
Arteterapia Gestalt. Y en todos ellos, una primera demanda por parte de los padres es encontrar herramientas, recursos para afrontar situaciones difíciles con sus hijos en el día día. Y éste es el problema: buscar fuera lo que ya está dentro, pretender que alguien nos cuente, nos diga lo que debemos hacer, buscar recetas elaboradas por otros para poder reproducirlas en casa, creyendo que siguiendo los pasos oportunos, alcanzaremos los resultados deseados. Esto tiene mucho que ver con la posición que solemos tomar en la vida, creyendo que la verdad está fuera, que para aprender hay que salir y buscar la información que otros tienen, que son los demás, los profesionales, los que saben. En cierta medida, el desconocimiento de nosotros mismos nos coloca en esta actitud de demanda y nos impide reorientar la mirada para comenzar a atendernos, a conocernos, a escucharnos y descubrimos. Estas propuestas destinadas a los padres, al igual que ocurre en terapia o en otros contextos, no tienen sentido si no se plantean desde el trabajo personal, desde el compromiso con uno mismo, desde el desmontaje de esquemas e ideas previas adquiridas y desde el cuestionamiento de estas verdades tan fijamente arraigadas en nosotros.

Me planteo el trabajo de manera que pueda devolver a los padres que están en esta búsqueda la conexión con su buscador interno, ayudarlos a ser más conscientes de sus dificultades y sus potencialidades, que puedan tomar contacto con sus emociones, con vivencias que han contribuido a la construcción de su carácter, posibilitar que empaticen y acojan a su niño interior, que lo atiendan, lo escuchen y lo traten con amor. En esta vuelta sobre sus propios pasos, en este descubrimiento de este mundo infantil que los acompaña aún sin saberlo, es posible que los padres adquieran mayor conciencia de su responsabilidad personal para con ellos y para con sus hijos, reorientando el tema y poniéndose ellos mismos en el foco del trabajo, dejando así que sus hijos puedan liberarse de la carga de ser ellos responsables del problema de la familia.

En este ejercicio de atención personal, cada parte del sistema toma lo suyo y el niño puede dedicarse a ser niño, dentro de los límites que los adultos marcan para su seguridad.

En su camino hacia el ser adulto, el niño pasa a interiorizar dentro de él al padre y a la madre, y así mismo, el adulto debe hacer el trabajo de reconocer su padre y su madre internos, y también al niño que fue y que sigue viviendo en él. En esta inmersión a nuestro mapa emocional, encontramos elementos que reconocemos como castrantes, limitantes y condicionantes, como la rigidez de la norma, la exigencia, la competitividad, el miedo, la imposición, la comparación; así como encontramos otros aspectos que necesitan ser atendidos y rescatados: la acogida amorosa, la confianza, la escucha sin juicio, el calor maternal. Todos nosotros necesitamos reconstruir un buen padre y una buena madre internos. Y eso pasa previamente por la necesaria expresión emocional de todo lo que no ha sido dicho, comunicado. El dolor por no ser reconocido, atendido, mirado con amor y confianza; el dolor por no ser visto completo, por el abandono y la falta de cariño. Los dolores del alma son los que impiden a los padres mirar a sus hijos de una manera completa, con confianza y respeto en su ser niños.

Con todo ésto, mi intención es llamar la atención sobre la necesidad de reorientar el trabajo con los padres más bien hacia su ser como personas que hacia la adquisición de técnicas y herramientas de aplicación rápida y directa, si bien 
éstas ayudan y facilitan la labor de ser padres en el día a día.

La labor que tienen que emprender los hombres, sin duda paralela a la de las mujeres, consiste en liberarse de las erróneas, distorsionadas y dolorosas identificaciones con sus padres. La idea es que debemos sanar el padre interior herido si deseamos convertirnos en mejores padres de nuestros niños interiores y exteriores.

(Osherson, 2010, p. 387)

\section{EI niño interior. Un acercamiento a los niños desde la propia vivencia}

\section{La sabiduría del niño}

Desde el planteamiento de la terapia gestalt, todos venimos a este mundo completos y a medida que vamos creciendo, en base a nuestra necesidad de pertenencia y de supervivencia, vamos perdiendo esa completud, negando partes nuestras, castrando nuestra sabiduría innata y moviéndonos por la vida con una máscara construida, creyendo que la necesitamos para enfrentarnos al mundo. Si bien es cierto que hacemos lo que podemos y que todos en un momento u otro sufrimos el trauma del desamor, del rechazo, del abandono, tener consciencia de la trascendencia de éste hecho, nos obliga a estar atentos con nuestros niños y niñas, entendiendo que tenemos la responsabilidad de verlos con otra mirada, una mirada de admiración y apertura, para poder aprender de ellos a entender la vida de otro modo, desde la sorpresa, desde el disfrute y el placer, desde lo más instintivo y con más sencillez.

Una parte importante del proceso de crecimiento personal, o más bien de decrecimiento personal, en el que muchas personas nos involucramos en algún momento de nuestra vida, pasa por volver al niño que fuimos, recuperar dentro de nosotros esa verdad que Somos, ese ser auténtico y genuino que nos conecta con la vida de una manera sencilla y gratificante.

El arquetipo del niño representa la plenitud humana, y estar en contacto con él nos confiere el valor para ser más humildes, más inocentes, ponernos en conexión con las pequeñas cosas que nos acercan a la felicidad.

El niño es el principio y el fin... El niño simboliza la naturaleza preconsciente y postconsciente del hombre, su plenitud... El "niño" es todo aquello abandonado y expuesto y, al mismo tiempo, divinamente poderoso; el principio insignificante e incierto y el fin triunfal. El "niño eterno" inherente al hombre es una experiencia indescriptible..., un imponderable que determina el valor o la falta de valor fundamentales de una personalidad.

(Jung y Kerenyi, Essays on a Science of Mythology, p.96).

Desde nuestra posición de adultos que hemos crecido, madurado, tenemos vivencias, experiencia y sabiduría, nos falla lo más importante de todo: reconocer que si no recuperamos al niño que fuimos y lo incorporamos en nuestra vida como algo clave en nosotros, estamos castrados de una parte fundamental de nuestro Ser, destinados a una vida desprovista de instinto, donde la razón come terreno a la 
intuición y a nuestro impulso más primitivo.

Muchas familias actuales, demasiado desconectadas a veces de las necesidades del niño interior, no pueden ponerse en sintonía con la crianza de sus hijos, perdiéndose la oportunidad en esta etapa de revivir su propia vuelta a ese territorio acogedor y generador de sabiduría que es la infancia. Las prisas, las exigencias de esta sociedad patriarcal en la que estamos inmersos, la necesidad de no ser devorados, de formar parte aún a riesgo de no saber dónde estamos metidos y cómo hemos llegado hasta ahí, el miedo a soltar, a dejarnos vivir a un ritmo propio,... todo esto nos impide disfrutar y aprovechar esta nueva oportunidad que la vida nos brinda cuando hay niños a nuestro lado: reconectarnos con nosotros a través de ellos, revivir lo que no pudimos, curar nuestras heridas de la infancia, atendernos en nuestra vulnerabilidad, en nuestra pequeñez, en nuestros miedos y deseos.

La educación no es que tenga que enseñar algo, sino que tiene que dar reconocimiento, darle la sensación al niño de ser visto, de ser considerado, y eso pasa por respetar sus deseos. Por eso es muy importante este aspecto de la educación activa: la consulta del deseo de los niños. En vez de ser un banco de datos, con uno que lo sabe todo ante unos ignorantes que no saben nada, la educación ha de tener un elemento de diálogo, en que el maestro respeta el ritmo de cada uno de sus alumnos, con maneras que permitan aprender de una forma alegre. Acompañados por un adulto no sabelotodo, sino por un modelo de no saber... que le haga sentir bien al niño o al joven. Alguien que acompañe en el descubrir. Un ser humano tiene una sabiduría orgánica. Así como las plantas buscan el sol, se orienta según un principio de placer: de lo que le da placer y lo que no.

(Naranjo, 2007).

Estar en contacto con niños nos permite descubrirnos en nuestro caos interno, en la creatividad latente en nosotros, en la posibilidad de crear, ausente el juicio y las expectativas, en el placer de mostrarnos sin miedo, en el disfrute de entrar en contacto con el otro, reconociendo mis espacios, los propios, los comunes.

Los espacios de creación con niñas y niños en los que participo, tanto en talleres creativos como en sesiones de arteterapia, me invitan sin duda a descubrirme como en otros contextos no puedo hacerlo, a soltar por un rato el control, la planificación $\mathrm{y}$ mis esquemas de cómo deben ser las cosas, y sumergirme en un espacio de autorregulación y de sinergia creadora en el que el grupo se va moviendo guiado por un motor común, por una sabiduría propia que entra en consonancia en la medida en que cada uno se deja estar con su deseo y su necesidad. Es muy bonito poder acompañarlos, entrando en contacto con ellos en esa búsqueda y en ese hacer libre y por momentos, retirándome a una posición de observadora y acompañante que acoge y sostiene todo lo que allí ocurre. Es por tanto una danza espontánea y libre, un ir y venir, como el movimiento de una ola que se retroalimentar a sí misma con la confianza de saberse parte de un todo más grande que la genera y la acoge. Creo que para los adultos, madres, padres y acompañantes como yo que dedican tiempo a los niños, es una suerte poder tener delante ese espejo tan reparador, esa llamada de atención que nos alienta a rescatar-nos, a identificarnos 
de nuevo con lo que fuimos y con lo que seguimos siendo, porque el niño interior no está perdido, aunque sí quizás dormido dentro de cada uno de nosotros.

\section{Explorando emociones. Mapa emocional en la familia}

Entiendo la familia como un nido. Esa imagen me ayuda a a invitar a construir un lugar, tanto interno como externo, en el que generar calor y acoger aquello que nace de dentro, alimentarlo, cuidarlo y ayudarlo a crecer y ser autónomo, para que así pueda emprender el vuelo y lanzarse a la vida, sabiendo que lleva dentro de sí el potencial para generar un nuevo nido, con el legado que trae de su propio recorrido y el de sus mayores. El amor es el motor que alimenta este anidar. (Ver fig. 2. Nido).
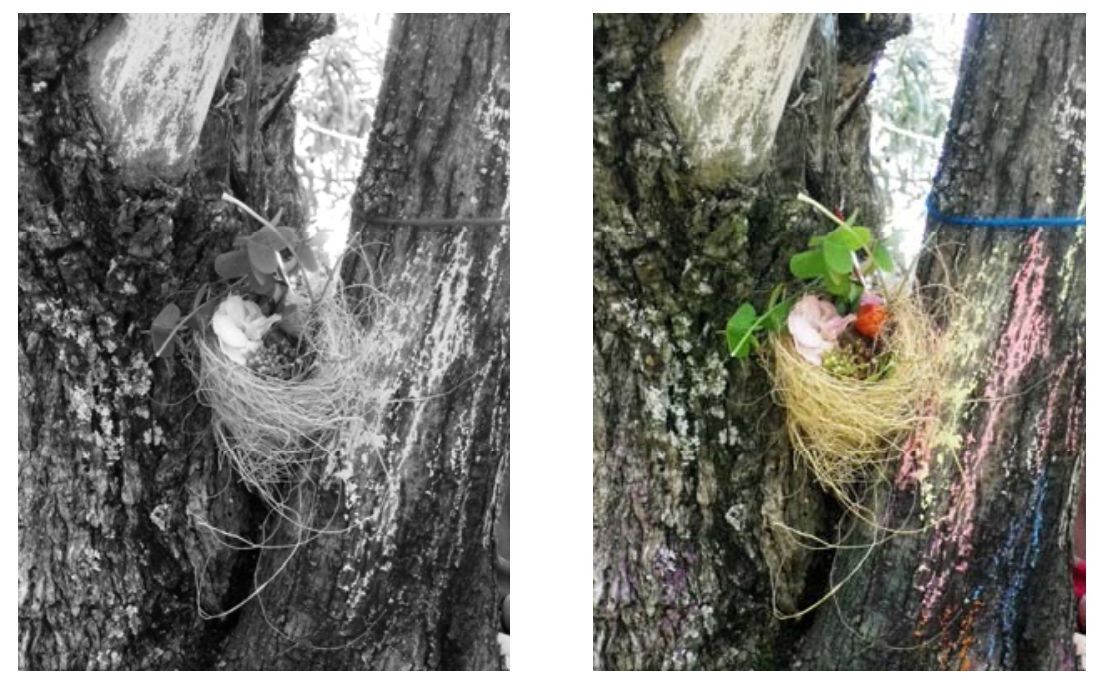

Figura 2. Nido

Esta imagen simbólica del nido aparece una y otra vez en las sesiones con los padres, potenciando la búsqueda de ese calor interno, transmitiendo la propia posibilidad de rehacer los espacios, habitarlos, incluso desmontarlos y volver a configurar ese lugar con otros materiales, otras formas, otros colores. Al mismo tiempo que trabajamos en la creación de la obra, vamos dejando brotar las emociones que nos acompañan en ese viaje: la tristeza, la añoranza, el dolor, el amor,...

En todo esto influye sobremanera la tipología de afecto de los propios padres. Podemos revisar el vínculo afectivo que se establece entre madre e hijo y saber que si son padres seguros de sí mismos y coherentes, los hijos podrán enfrentar la vida con confianza y seguridad. Si por el contrario, los adultos son personas rígidas o excesivamente protectoras, los hijos pueden vivir la vida con preocupación, enfado o pasividad. En otros casos, los adultos resultan ser caóticos, sin organización interna y esto puede generar en los pequeños desorientación, falta de iniciativa y voluntad o exigencia. Hay padres poco emocionales, distantes, que evitan el contacto. Los hijos de estos progenitores suelen tener dificultad para el contacto 
físico y son evitativos. Por tanto en muchos procesos grupales surge la necesidad de algunos padres y madres de buscar un acompañamiento individual paralelo para poder adentrarse en esa exploración propia, deshacer los pasos, volver atrás desde la conciencia de que tenemos que actualizar la experiencia que quedó bloqueada en algún momento de nuestra trayectoria infantil, trayéndola aquí y ahora para elaborar lo que queda pendiente.

La relación emocional requiere una conciencia atenta a nuestros estados internos y también apertura, comprensión y respeto por el estado mental de nuestros hijos. Tenemos que llegar a ver la situación no sólo desde nuestro punto de vista, sino también desde el suyo. Sin embargo, ésta puede ser una tarea sumamente ardua en el caso de que no seamos conscientes de nuestras emociones o de que estemos bloqueados por nuestros temas residuales o irresueltos y las reacciones emocionales que se derivan de ellos.

(Siegel y Hartzell, 2005, p. 87).

En este proceso de autoconocimiento podemos revisar si nos movemos con los pequeños en una excesiva proximidad o en excesiva distancia, generando espacios muy estrechos de poca libertad de movimiento o bien colocándonos demasiado lejos de ellos, perdiendo el contacto y la cercanía. Esta combinación de proximidad-distancia es la que ayuda a mantener el equilibrio, al igual que la polaridad dependencia-independencia, acción-retirada, reflexión-emoción. El trabajo con polaridades es fundamental en el proceso de creación en familia, observando cómo entre esos polos aparentemente opuestos, generamos un mapa con infinidad de puntos que nos invitan a pararnos y reconocernos más lejos o más cerca del equilibrio que implica la integración. En la obra y en el uso del material queda siempre constancia de la dinámica familiar, visibilizándose como cada elemento interactúa, expresa, reclama, ocupa espacio, lo cede, pelea, se acerca, se retira...

Explorar lo desconocido, la parte de nosotros que solemos proyectar fuera, o negar o desplazar, es un rico ejercicio de apertura que nos pone en contacto con esa parte que necesitamos para ser y vivir más completos. Ese aprendizaje es posible transmitirlo a los más pequeños, dándoles la posibilidad de reconocerse, contradecirse, probar y equivocarse, desde la propia libertad experimentada en el adulto y contagiada al niño.

El derecho al error es un valor fundamental que nos abre a la vida, con conciencia y responsabilidad. La negación del fallo y el castigo nos cierran a la experiencia, minan nuestra autoestima y nos colocan en una posición de no merecimiento. La dificultad que tenemos los adultos para entender que el error forma parte del aprendizaje, que necesitamos vivir y fallar para saber de qué trata ésto que es el vivir, es la misma dificultad que tenemos cuando los pequeños no se ajustan a lo que se espera de ellos, no van al ritmo de otros, al supuestamente aceptable, no demuestran, no brillan, no aciertan. Si los adultos sabemos reconocer nuestros propios fallos, podremos devolver a los pequeños una mirada más amorosa y respetuosa, mirar con compasión ese proceso de crecer en el que están inmersos, sin prisas, sin modelos rígidos preestablecidos. De nuevo en la obra está 
implícita esa posibilidad de fallar, probar y volver a intentarlo, siendo el espacio de creación flexible y tolerante, receptivo con la totalidad de los elementos que aparecen, sean o no entendidos como algo definitivo o resolutivo.

Un aspecto fundamental en el desarrollo emocional del niño y de la familia es trabajar la tolerancia a la frustración, saber esperar, observar, escuchar, estar atentos, confiar, ser pacientes, dar al tiempo y al silencio su lugar, dar espacio para que de ahí surjan nuevas vivencias, sin atropello. En este aprendizaje los adultos debemos ser acompañantes, intermediarios que puedan cuestionar las prisas impuestas por la sociedad, bajar a un ritmo más lento y enseñar a los niños la riqueza que se haya escondida en el propio no-hacer o hacer-nada. Absortos por la idea de que hemos de ser productivos, resolutivos, trabajadores, nos olvidamos de que a veces no tenemos que producir, sino más bien aprender a estar en presencia con lo que hay; dejar de resolver y aceptar lo que la vida nos muestra y nos regala, sin pelea; entender el trabajo como una fuente de disfrute y placer gracias al cual ponemos nuestro potencial a disposición de otros. En la experiencia en Arteterapia este hacer desde el disfrute, desde la no exigencia, atendiendo al proceso más allá del resultado, nos conecta con otro ritmo, con el sentido que el crear tiene en sí mismo, como contexto de vinculación directa con el Ser, y no tanto con el hacer o el parecer.

Dentro del trabajo emocional juega un papel muy importante la comunicación y el contacto con el mundo, con los otros. En la medida en que el niño tiene una sana autoestima, es capaz de comunicar más y mejor, desde su seguridad y la libertad de mostrarse tal y como va surgiendo de su interior. Desde la gestalt es necesario revisar los tres canales desde los que podemos comunicarnos, ya sean el mental, el emocional o el instintivo. Así pues, también registrado en la obra artística en el proceso arteterapéutico, es posible adentrarnos en ella y en su contenido desde esta triple visión: "Yo pienso..., yo siento..., yo necesito...", o bien "la obra me hace sentir... y pienso, y surge mi necesidad de...". Aprender a comunicar es una manera de concedernos espacio en el mundo, ante los otros y con los otros, verbalizando aquello que experimentamos, compartiendo los procesos por los que transitamos y poniéndonos en una actitud de escucha activa para poder encontrarnos con el otro en el compartir y en el crecimiento mutuo. Hablar en primera persona, en presente, haciéndonos cargo de nuestro deseo y nuestra necesidad. Y en la obra, actualizar una y otra vez la experiencia, reconocer lo que emerge, a veces de manera sutil, otras con evidencia, y darle curso en el hacer creador. Así, son aspectos esenciales tanto en la creación como en la propia vida, la sensibilidad para dejarnos estar, contagiarnos de lo que nos rodea, admirar la sencillez, la belleza, el caos, lo confusión, lo sutil. La sorpresa nos coloca cerca de los niños, nos ayuda a percibir las cosas sin tantas expectativas, más en contacto con lo real. La sorpresa en lo real... bonita experiencia.

\section{Recuperar espacios de exploración y disfrute}

Los contextos de trabajo en familia son espacios de autocuidado en los que autoregularnos, en los que revisarnos y en los que crecer y disfrutar juntos, buscando nuevos puntos de vista, otras perspectivas, miradas alternativas a las que solemos tener. 
La creación artística propicia un ambiente fértil, un espacio intermedio de encuentro para generar posibilidades que nos saquen de dinámicas repetitivas y cerradas. (Ver fig.3. Creando y disfrutando en familia).

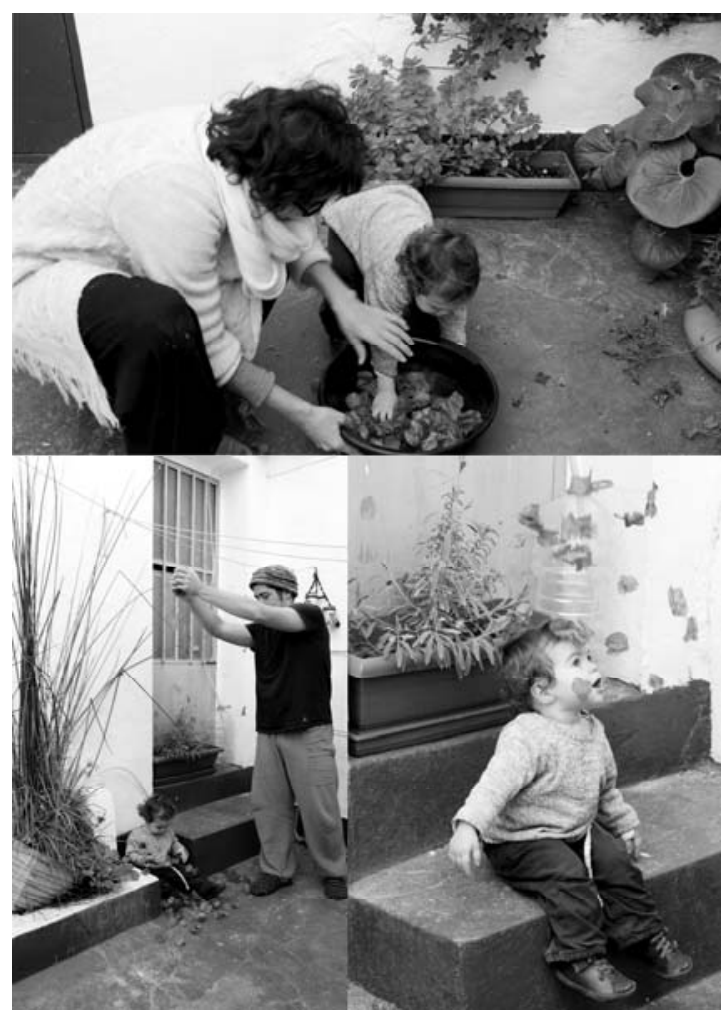

Figura 3. BN. Creando y disfrutando en familia.

Hacer por hacer, estar, conectarnos desde nuestro presente, sin mayor pretensión. En el acto de crear, prescindimos por un tiempo de tener que argumentar lo que hacemos, pasamos del discurso conocido a un lenguaje cargado de información y de elementos que se ponen de manifiesto, desde lo simbólico, desde la metáfora. La materia se convierte en un catalizador de las emociones que surgen y al manipularla y transformarla, vamos adentrándonos en un mundo que nos conecta con nosotros mismos, que nos ayuda a descartar lo supérfluo y a mirar lo importante.

El sentido de estos espacios es el intercambio, el placer de dar y recibir, el ofrecer algo nuestro y confiar en que el otro lo tome, el aprender a pedir y a tomar lo que el otro quiere entregarnos a nosotros. El ritmo es el que cada grupo va marcando, ningún otro ritmo es mejor. Muchos adultos están acostumbrados a dar siempre y muchos niños están en el recibir continuo. Es bueno por eso que adultos y niños prueben a cambiar de lugar, que los adultos tomen y los niños puedan ponerse en disposición de ofrecer.

Los contextos de trabajo vinculados a la naturaleza son especialmente ricos y 
sugerentes. Sentir el ritmo de la vida que fluye a nuestro alrededor, sensibilizarnos con ese fluir y poder acompasarnos a él, sintiendo que esa vida está dentro y fuera, que somos parte de ella. Los trabajos de Arteterapia en la naturaleza ofrecen materiales y recursos muy especiales, que alimentan el espíritu y nos ayudan a sintonizarnos con la familia de la que formamos parte, a generar rituales que den muestra de actitudes de apertura, de comunicación, de cambio, de agradecimiento, de pertenencia.

Sin duda, una oportunidad para crecer en el otro y con el otro en mí.

\section{Reflexiones finales}

Me resulta curioso que me encuentre yo escribiendo a cerca de este tema sin ser madre biológica, que la vida me esté poniendo constantemente en contacto con experiencias en las que se me brinda la posibilidad de conectarme y acercarme a mi niña interior, de exponerme a situaciones en las que descubrirme continuamente en ese acompañamiento a los demás, en esa escucha sensible y respetuosa al niño que tengo delante, a la niña que fuí, a sus necesidades y a las mías, al adulto que, como yo, busca y necesita soltar su construcción elaborada a base de tanto esfuerzo y compostura, para retomar lo que quedó interrumpido, nuestro Ser más auténtico. Este camino en el que tengo la suerte de acompañar a otras personas, es mi propio camino, y pongo todo de mi parte, me nutro, me muestro y me entrego a este crecer juntos que es el trabajo creativo y el proceso terapéutico, con respeto y confianza, cada uno desde el lugar que le toca vivir.

Los niños buscan lugares de acogida para rendirse a su ser niños, espacios seguros donde comprobar que pueden confiar, que tienen margen para probar y explorar el mundo, que pueden ir y volver, que no hay un error en ellos, que son completos y valiosos en sí mismos, que pueden sentir la libertad y el placer, el dolor y la alegría y que, con todo ello, son bienvenidos. Este universo que comparto con ellos, cargado de símbolos, metáforas, imágenes, espacios y emociones, me recuerda constantemente que la vida es movimiento, que siempre podemos reparar emocionalmente lo que en un momento dado no pudo ser, que todos tenemos dentro un potencial maravilloso que nos vincula a la vida y que nos impulsa a buscar el equilibrio que necesitamos, desde lo más profundo, pasando por el cuerpo, atendiendo a nuestra sabiduría innata para autoregularnos y atendernos en nuestra necesidad presente.

Desde mi no-saber, desde el respeto profundo que siento por las personas y familias con las que trabajo, me muestro, me expongo y me arriesgo. $\mathrm{Y}$ en ese continuo descubrimiento vamos creciendo. Como decía el gran maestro espiritual Nisargadatta Maharaj, "Siéntase perdido! Mientras se sienta competente y seguro, la realidad está más allá de su alcance. A menos que acepte la aventura interior como modo de vida, el descubrimiento no llegará a usted". "Olvide sus experiencias y sus logros, quédese desnudo, expuesto a los vientos y lluvias de la vida, y tendrá una oportunidad". 


\section{Referencias bibliográficas}

Cavallé, M. (2016). La sabiduría recobrada. Filosofía como terapia. Barcelona. Editorial Kayrós.

Garriga, J. (2013). El buen amor en la pareja. Cuando uno y uno suman más que dos. Barcelona. Ediciones Destino.

Harrison, S. (2005). La infancia feliz. Un cambio en la naturaleza de la educación. VitoriaGasteiz. Ediciones La Llave.

Hoshino, J. (2015). Family Art Therapy. The Wiley Handbook of Art Therapy, 210.

Naranjo, C. (2013). Cambiar la educación para cambiar el mundo. Barcelona. Ediciones La Llave.

Palou, S. (2013). Sentir y crecer. El crecimiento emocional en la infancia. Propuestas educativas. Barcelona. Editorial Graó.

Siegel, D. y Hartzell, M. (2005). Ser padres conscientes. Vitoria-Gasteiz. Ediciones La Llave.

VV.AA. (2010). Recuperar el niño interior. Barcelona. Editorial Kairós. 